\title{
Editorial
}

\section{Cutting Edge without Cutting Corners: Bronchoscopic Treatment for Bronchial Carcinoids}

\author{
H.A.P. Brokx T.G. Sutedja \\ Division of Thoracic Oncology, VU University Medical Center, Amsterdam, The Netherlands
}

In this issue of Respiration Katsenos et al. [1] report on the long-term palliation by bronchoscopic treatment of a patient with recurrent atypical carcinoid. They show that multiple recurrences of a bronchial carcinoid can be controlled with local, i.e. bronchoscopic, treatment over a long period of time. It is of special interest that although the initial treatment modality in this case was surgical resection, i.e. 'enucleation' as described, the tumor recurred at another site in the lungs 9 years later, making surgical resection necessary. In the course of many years of follow-up, several recurrences developed and were treated sufficiently by bronchoscopic means and by liver segmentectomy for a distant metastasis.

The gold standard for treatment of bronchial carcinoids traditionally has been radical surgical resection. From an oncologic point of view, radical surgery should be regarded as the standard approach. However, more conservative resection is now considered to be an accepted strategy in the treatment of bronchial carcinoids because it is more parenchymal sparing with justifiable long-term survival results for a disease entity that may harbor a low malignant potential [2-4]. Some authors advocated more aggressive therapeutic approaches based on the classification of atypical histology [5].

\section{KARGER \\ Fax +4161306 1234 \\ E-Mail karger@karger.ch}

www.karger.com
(C) 2011 S. Karger AG, Basel

$0025-7931 / 11 / 0814-0285 \$ 38.00 / 0$

Accessible online at:

www.karger.com/res
In line with this normal tissue-sparing approach, bronchoscopic treatment has been utilized in selected patients who were either unfit to undergo surgical resection or who had too extensive disease progression and were treated in a palliative setting, for tumor located in the central tracheobronchial tree.

Current understanding of tumor growth and behavior with regard to the development of local and distant disease has enabled us to consider alternative strategies that are aimed toward optimal outcome in terms of maximum preservation of quality of life. Furthermore, an increased use of minimally invasive techniques has improved our abilities for a more tailored approach and evaluation of disease processes, allowing us to consider more balanced tissue-sparing alternatives to surgical intervention. A tendency towards tissue-preserving treatment modalities, respecting oncologic principles, accounts for treatment in nearly all fields of oncology nowadays. With respect to the treatment of bronchial carcinoids, more and more authors report on ever-expanding tissue-preserving curative modalities (i.e. intraluminal bronchoscopic treatment) as sound alternatives to (immediate) surgical resection. They increasingly question the firmly based dogma that surgical resection is the only justifiable treat- 
ment option because it is based on histology classification which is of utmost importance in clinical decision making (i.e. typical vs. atypical histology) [6, 7]. However, with the current understanding of tumor biology these aspects should be taken into account in a wider perspective [8-10].

The initial treatment by Katsenos et al. ('enucleation'), the treatment of the tumor that recurred at another site in the lungs 9 years later with surgical resection and the treatment of several recurrences that developed by endoscopic means including liver segmentectomy for a distant metastasis all point out that natural tumor biology possibly would not have been influenced by what was considered to be the primary treatment of choice, i.e. more extensive radical surgical resection in case of atypical carcinoid tumor classification alone. If primary treatment had been bronchial treatment, would that have changed the outcome? Bronchoscopic treatments may alleviate symptoms, but are more parenchyma-sparing treatment approaches detrimental for the outcome?

Still, our knowledge and attitude towards bronchial carcinoids and their histologic classification, natural biology and treatment modality appear to be lacking for only justifying radical surgical resection in selected patients above bronchial treatment.

Our classification, based on work by Travis et al. [8], might not be sufficient for all bronchial carcinoids, as this classification is based on surgically resected specimens, possibly representing other tumor subtypes as opposed to centrally located bronchial carcinoids. There are atypical subtypes with more malignant potential and with a higher tendency to recur and/or metastasize despite (aggressiveness of) treatment versus a more docile subtype. Even the atypical type with more frequent nodal and distant metastases can have a protracted natural disease of several years' duration.

Especially in dealing with a clinically less malignant tumor type and in light of increasing recognition of the long lead time that may occur, one needs to continuously reflect and remain vigilant to do parenchyma-sparing resection whenever feasible.

In conclusion, numerous questions still have to be answered as regards tailoring the best approach towards our understanding and subsequent treatment of this intriguing neuroendocrine tumor entity.

\section{References}

1 Katsenos S, Rojas-Solano J, Schuhmann M, Becker HD: Bronchoscopic long-term palliation of a recurrent atypical carcinoid tumor. Respiration 2011;81:345-350.

$\checkmark 2$ Okike N, Bernatz PE, Woolner LB: Carcinoid tumors of the lung. Ann Thorac Surg 1976;22:270-277.

3 Stamatis G, Freitag L, Greschuchna D: Limited and radical resection for tracheal and bronchopulmonary carcinoid tumour. Report on 227 cases. Eur J Cardiothorac Surg 1990;4:527-532.

$\checkmark 4$ El Jamal M, Nicholson AG, Goldstraw P: The feasibility of conservative resection for carcinoid tumours: is pneumonectomy ever necessary for uncomplicated cases? Eur J Cardiothorac Surg 2000;18:301-306.
5 Marty-Ané CH, Costes V, Pujol TL, et al: Carcinoid tumors of the lung: do atypical features require aggressive management? Ann Thorac Surg 1995;59:78-83.

$\checkmark 6$ Luckraz H, Amer K, Thomas L, et al: Longterm outcome of bronchoscopically resected endobronchial typical carcinoid tumors. J Thorac Cardiovasc Surg 2006;132:113-115.

$>7$ Brokx HAP, Risse EK, Paul MA, et al: Initial bronchoscopic treatment for patients with intraluminal bronchial carcinoids. J Thorac Cardiovasc Surg 2007;133:973-978.
$>8$ Travis WD, Rush W, Flieder DB, et al: Survival analysis of 200 pulmonary neuroendocrine tumors with clarification of criteria for atypical carcinoid and its separation from typical carcinoid. Am J Surg Pathol 1998;22: 934-944.

$\checkmark 9$ Walch AK, Zitzelsberger HF, Aubele MM, et al: Typical and atypical carcinoid tumors of the lung are characterized by $11 \mathrm{q}$ deletions as detected by comparative genomic hybridization. Am J Pathol 1998;153:1089-1098.

10 Skov BG, Krasnik M, Lantuejoul S, Skov T, Brambilla E: Reclassification of neuroendocrine tumors improves the separation of carcinoids and the prediction of survival. J Thorac Oncol 2008;3:1410-1415. 